\title{
Espacios públicos: Espacios acuáticos
}

\author{
CAROLINA GONZÁLEZ ViVES \\ Arquitecto. Profesor asociado Área de Proyectos Arquitectónicos. Escuela de Arquitectura \\ Universidad de Alcalá \\ cgonzalesvives@gmail.com
}

\begin{abstract}
Resumen
La integración del agua y los procesos hidrológicos dentro de la ciudad, como la lluvia, los charcos, las crecidas o la evaporación, que definen las condiciones de formación de un paisaje, son una fuente de identidad y de carácter para el espacio público urbano frente a lo anodino y banal (Muñoz, 2008) de muchas áreas de reciente crecimiento. Al dar cabida a la variabilidad de la hidrología en el ámbito de lo público, se trascienden los beneficios ambientales que evidentemente supone para incorporar contenidos simbólicos y estéticos asociados al agua, que enriquecen sensorialmente el espacio y la experiencia somática que nos ofrece, y da pie a la construcción de verdaderos lugares antropológicos.

A lo largo de las últimas décadas del siglo XX, desde la disciplina de la arquitectura se han ido elaborando sucesivas conceptualizaciones de la ciudad como una estructura espacial continua, no objetual, con un carácter sobre todo horizontal aunque con espesor (Allen, 1999), por cuyos vacíos discurren y se almacenan aire, agua, energía e información. Estas referencias a la estructura urbana como un paisaje poroso, esponjoso, interconectado y atravesado por diversos flujos, sugieren la imaginación de otra relación con el agua, la idea de ciudad como mecanismo filtrante, un paisaje de captación y retención del agua de lluvia, capaz de empaparse, muy diferente de la construcción actual, de superficies impermeables y sistemas de alcantarillado por donde desaparece el agua de forma casi instantánea.

En el espesor de esta estructura porosa, los vacíos de mayor escala corresponden con ámbitos de carácter público y monumental, donde la dimensión del espacio y la presencia del agua se vuelven significativas en la ciudad. En estos huecos, la coincidencia entre las geometrías de reunión en los espacios públicos y las formas de convergencia del agua, ambas referidas a lo cóncavo, presentan un gran potencial para la superposición de programas y la asociación de contenidos simbólicos, integrando en los mismos espacios contenidos cívicos con ambientales, y formalizando una monumentalidad propia del paisaje urbano que se refiere a ese nuevo parlamento entre humanos y no humanos (Latour, 1997).
\end{abstract}


Estas formas cóncavas, que como tipo arquitectónico se remontan a los teatros griegos, tienen la capacidad de abstraer el agua de los entendimientos científicos y ambientalistas, al separarse del exterior y centrar la atención hacia el interior, para poner de manifiesto lo estético y de alguna forma enmarcarlo, objetualizarlo, y acercarse a un proceso de monumentalización.

Palabras clave: Agua; espacio público; hidrología; identidad; monumentalidad; ambientalismo.

\title{
Public spaces: Acuatic spaces
}

\begin{abstract}
Water and hydrological process, as rain, puddles, overflows or evaporations, define landscape essential conditions, integrating them within the city contributes to build urban public space's identity and character, needed to transform many growing areas that are anodyne and banal (onMuñoz, 2008). Making place for hydrological variability in the public realm goes beyond the environmental benefits to incorporate aestetic and symbolic contents related to water, that enrich space and the somatic experience that it offers, and enable the construction of proper anthropological places.

During last decades of the 20th century, architects have proposed sucessive concepttualizations about the city as a continuous spacial structure, non objectual, mainly horizontal but with a certain thickness (Allen, 1999). Throught its voids flow air, water, information and energy. These references to urban structure as a porous and spong-like landscape, suggest the imagination of a different relationship with water: the city as a seeping mechanism, as a rainharvesting landscape, able to soak, in a totally different way to the current impervious surfaces and drainlet systems, where water dissapears almost inmediatly.

In the thickness of this porous megastructure, bigger voids correspond with the public and monumental sphere, where the spatial dimension and the water presence turn mea-ningfull to the city. In these hollows, geometrical coincidence between meeting and water gathering forms, both related to concavities, present an interesting potential for mixing uses and combining symbolic contents. To integrate civic and environmental programs, makes way to an urban landscape own monumentality, that referst to this new parlament between humans and non humans (Latour,1997).

These concave shapes, that as an architectural prototype reaches the greek theather, have the hability to take out water from scientific and environmental visions. To separate it from the outside and focus the atention to the inside is in someway to frame it, to objectify it, in order to highlight the aesthetics and aproach a certain way of monumentality.
\end{abstract}


Key words: Water; public space; hydrology; urban identity; monumentality; environmentalism.

Sumario: 1.- La ciudad como una estructura porosa, filtrante. 2.- Geometrías políticas: geometrías acuáticas. 3.- El agua como centro del espacio. 4.- Construcción de lugares y experiencia somática. 5.- Ambientalismo monumental. 6.. Referencias bibliográficas.

\section{La ciudad como una estructura porosa, filtrante.}

A lo largo de las últimas décadas del s. XX, desde la disciplina de la arquitectura se han ido elaborando sucesivas conceptualizaciones que entienden y explican la ciudad como una estructura espacial no objetual sino continua, con un carácter sobre todo horizontal aunque con espesor (Allen, 1999). Por los vacíos de esta estructura discurren y se almacenan aire, agua, energía e información. Las imágenes elaboradas en los 60 y los 70, como las megaestructuras de Reyner Banham ó Yona Friedman y los matbuildings de los Smithson proponen un entendimiento de la ciudad como un único sistema espacial, donde figura y fondo no son diferenciables. También Andrea Branzi, en su obra The weak metrópolis describe un modelo basado en la indefinición funcional, construido con perímetros fluidos y atravesables. Branzi propone la disolución de los límites entre interior y exterior, entre lo público y lo privado, para sustituirlos por un sistema que funcione por intensidades y gradientes, como un acondicionamiento ambiental general del espacio, que produce una textura urbana y un territorio integrado y sin especializaciones.

Estos proyectos han sido el germen de algunas ideas contemporáneas bastante influyentes, como la importancia de los flujos en el urbanismo, la preocupación por la atmósfera y el acondicionamiento de los espacios exteriores y sobre todo la incorporación de la idea de paisaje urbano, y posteriormente las herramientas de la ecología y el paisajismo al pensamiento de la ciudad.

Estas imágenes donde la ciudad es como un paisaje poroso, esponjoso, interconectado y atravesado por diversos flujos, sugieren la imaginación de otra relación con el agua, la idea de ciudad como mecanismo filtrante, un paisaje de captación y retención de lluvia. 
Revisando la ciudad histórica con esta idea en mente, podemos identificar y entender procesos que dan otro sentido a lo construido.

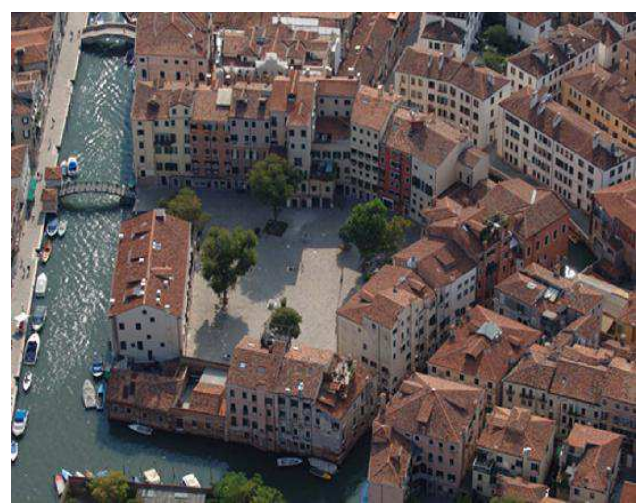

Fig. 1. Venecia vista aérea.

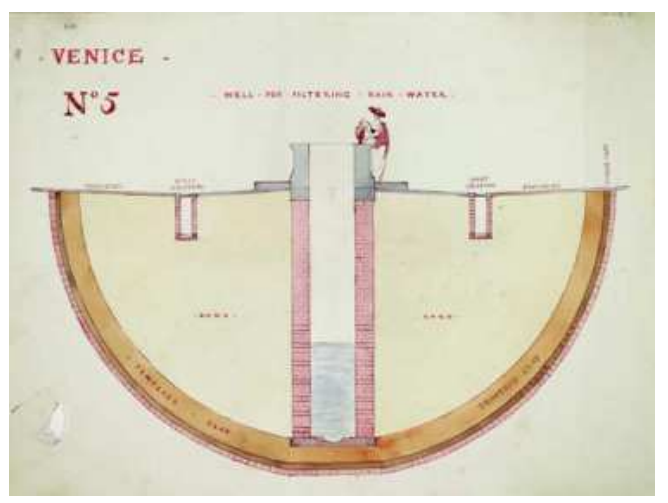

Fig. 2. Sección de las cisternas y pozos de los campi.

A lo largo de los siglos, las aportaciones de sedimentos que los ríos Po y Piave arrastran de las montañas, formaron una fina barrera que separa el lago de mar abierto. Así aparece un cuerpo de agua salobre de muy reducida profundidad, donde se ubica la ciudad. La modificación de los caudales de los ríos, de los cuales se toma agua para abastecer a las poblaciones, ha transformado este ecosistema, que se saliniza progresivamente. A pesar de su paisaje acuático y las frecuentes precipitaciones, Venecia ha tenido siempre que resolver con dificultad el abastecimiento de agua potable. La retención de la lluvia fue desde los orígenes un objetivo primordial, construyéndose el resto de los programas urbanos en torno a los sistemas de captación y filtrado.

Los campi venecianos son construcciones que forman pequeñas cuencas de drenaje que se superponen con los espacios públicos y sociales como un paisaje construido de acuíferos de agua dulce. Los mismos materiales que dan lugar de manera natural a la formación de acuíferos, se trasladan de la lógica de formación del paisaje a geometrías más precisas y escala más reducida. La ciudad crece como una adición de unidades filtrantes en torno a las cuales se organiza la vivienda y el resto de programas. Una capa gruesa de arcilla, de $1 \mathrm{~m}$ aproximado de espesor, separa del agua de la laguna un recinto de arenas permeables. En el interior de este recinto el agua se filtra y se almacena, hasta que se extrae de vuelta mediante un pozo central. Las cubiertas lógicamente 
se inclinan para verter el agua a la plaza y las pendientes del pavimento conducen el agua hacia unos sumideros que distribuyen el caudal en el volumen del filtro de arena. La ciudad completa funciona como un sistema de filtración y almacenaje de agua, como una esponja formada por acuíferos sucesivos. La plaza (campo) superponía un espacio público de reunión con la distribución de agua del pozo.

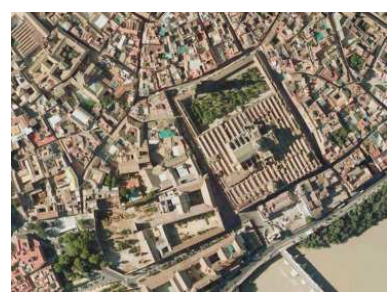

Fig. 3.

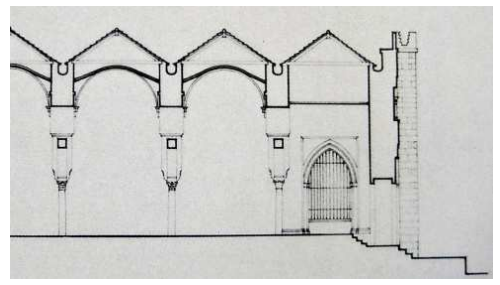

Fig. 4.

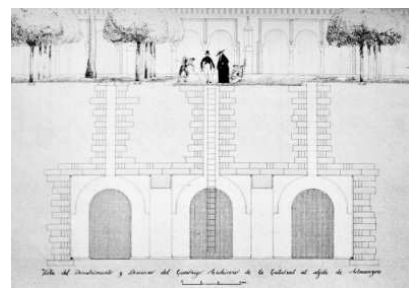

Fig. 5.

Vista aérea de Córdoba.

En las ciudades islámicas, de escala pequeña, tejido continuo, de carácter laberíntico, los grandes edificios también superponían históricamente funciones públicas y representativas con la gestión de agua. La mezquita de Córdoba por ejemplo, con la superficie de sus cubiertas y la oquedad que forma el patio, es una estructura de captación de escala bastante significativa para la ciudad. El estriado de la cubierta, con canalones lineales, que alcanzan hasta dos metros de profundidad, conduce el agua de lluvia que converge en el patio de naranjos. En el patio, la cisterna subterránea filtra y almacena el agua, que se destina a la fuente de abluciones previa a la entrada y al riego de la retícula de naranjos mediante un sistema de canales conectados.

Fig. 6. La fosse dionne en Tonnerre, Borgoña. Francia.

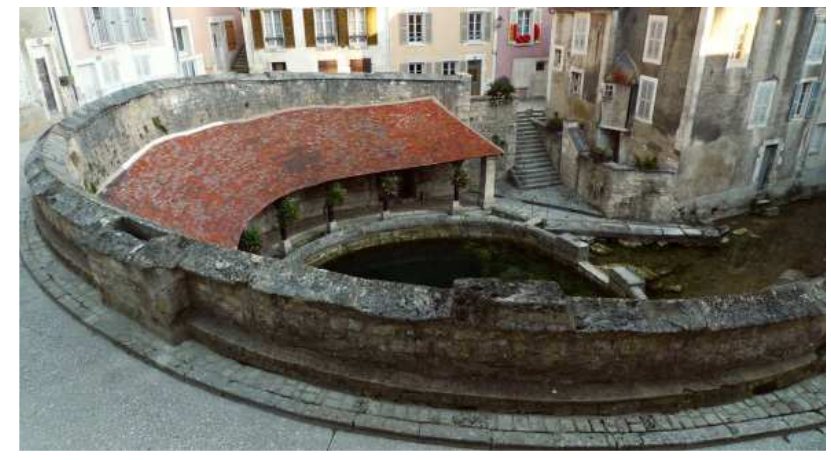


Con un programa diferente, los lavaderos franceses constituyen lugares singulares de la ciudad donde mediante geometrías cóncavas se almacena el agua, o bien se orada la superficie del suelo para permitir que aflore el agua del subsuelo. La Fosse Dionne en Tonnerre, Borgoña es una fuente de agua subterránea que surge en el casco histórico, en el espacio denso de la ciudad se abre paso una piscina central que recoge agua de lluvia del entorno urbano más próximo, y a través de un canal se comunica con el río.

\section{Geometrías políticas: geometrías acuáticas.}

En el espesor de esta estructura porosa, filtrante, las concavidades de gran escala, corresponden con ámbitos de carácter público y monumental, donde la dimensión del espacio y la presencia del agua son muy significativas en la ciudad. En estos huecos, la coincidencia entre las geometrías de reunión en los espacios públicos y las formas convergencia del agua, ambas referidas a lo cóncavo, presentan un gran potencial para la superposición de programas y la asociación de contenidos simbólicos.

Pitch África es una propuesta contemporánea basada en esta identidad formal. Patentada por Atopia Research, superpone la construcción de pequeños estadios de fútbol con motivo del mundial de 2010 y la captación de agua de lluvia para resolver el grave problema de escasez en este continente ${ }^{1}$. La identificación del estadio como tipología con las geometrías cóncavas favorables a la gestión del agua transforma estos edificios, ideados para construirse en cualquier parte con materiales que haya a mano, en una infraestructura de abastecimiento descentralizada, capaz de suministrar agua suficiente para 1000 personas a lo largo de todo un año.

\footnotetext{
${ }^{1}$ La pobreza está estrechamente vinculada a la falta de agua, y de acuerdo con la OMS, 1billon de personas carecen hoy de agua potable. Sin embargo el problema de escasez está más relacionado con la falta de infraestructuras adecuadas que con la falta de agua. Con una precipitación anual de $200 \mathrm{~mm}$, normal en las zonas áridas, (en Madrid contamos con $420 \mathrm{~mm}$ ) una superficie de captación de $36 \mathrm{~m}^{2}$ asegura un consumo de 20 litros diarios, suficiente para resolver las necesidades de agua potable básicas, (beber y cocinar). Actualmente se estima que las mujeres invierten 400 billones de horas de trabajo anuales solo para conseguir esta cantidad. La agricultura es en muchos sitios la posibilidad de escapar a la pobreza, y depende también de la adecuada gestión de la lluvia, que se concentra en un periodo corto del año y se evapora en gran parte.
} 


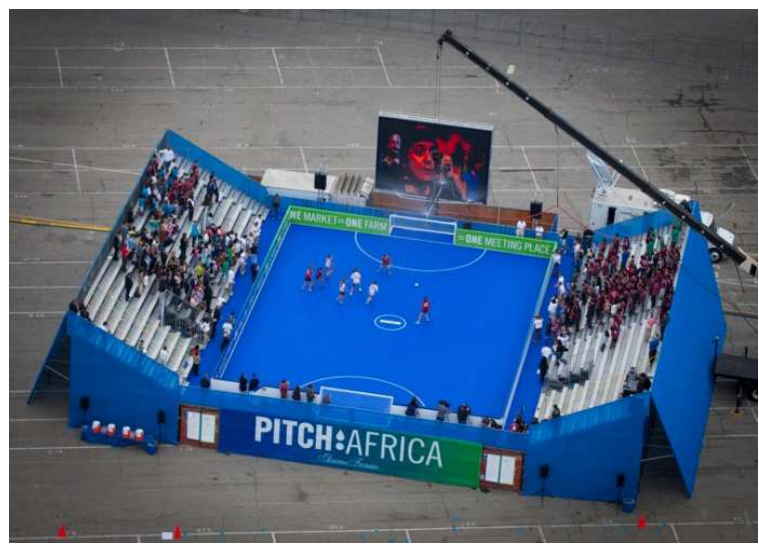

Fig. 7. Imagen de Pitch Africa. Fuente: Atopia Research

Las dos últimas reivindicaciones de la patente explican su funcionamiento:

[0020] un estadio captador de agua de acuerdo con el invento incluye unas gradas, una superficie de juego que funciona por lo menos en parte como un dispositivo de captación de agua, un depósito de agua que puede ser un tanque sectorizado, situado debajo de la superficie de juego para captar y almacenar el agua que pasa a su través. Un dispositivo de salida de agua está asociado al depósito, de forma que el agua es accesible para el consumo u otros usos. El graderío es impermeable de forma que dirige el agua hacia el campo de juego.

[0021] la superficie de juego incluye capas múltiples que funcionan respectivamente como filtros para materiales gruesos, filtro para finos, y sistema portante, y el dispensador de agua incluye un sistema de filtrado de agua. Las salidas pueden ser dispuestas a lo largo del perímetro del depósito. El tanque segmentado que constituye el depósito puede ser conformado a base de contenedores de barco.

\section{El agua como centro del espacio.}

La identidad entre formas cóncavas y espacios cívicos de reunión aparece de forma continua a lo largo de la historia de la arquitectura. El anfiteatro griego, normalmente asentado sobre una topografía favorable, consolida una tipología esencial para los espacios de reunión que agrupa a las personas en torno a un centro, aportando visibilidad para todos. Es muy interesante observar que estas construcciones absolutamente sociales no fueran círculos cerrados sino abiertos, permitiendo visuales en uno de sus lados que incorporan al paisaje a esta reunión.

Posteriormente, este tipo evoluciona y adopta en la arquitectura romana una forma totalmente cerrada e introvertida, donde de una manera diferente se incorpora la naturaleza en el interior del espacio: las naumaquias por ejemplo, son espectáculos donde el escenario se inunda y dan lugar a esta si- 
tuación de sentarse alrededor del agua, de volcar lo público alrededor del agua, que ocupa un lugar central. Sus cualidades físicas y plásticas la convierten en un fondo de escena privilegiado dentro de este ámbito aislado del exterior, que manifiesta a la vez que consolida, su papel en la vida pública urbana. En estas imágenes se incluye claramente una idea de centralidad en torno al agua, pero a diferencia de las estructuras de captación de Venecia o de Córdoba, o en su versión contemporánea de los estadios de fútbol donde el agua apenas es visible, aquí se superponen contenidos plásticos, simbólicos y lúdicos a estos nuevos espacios.
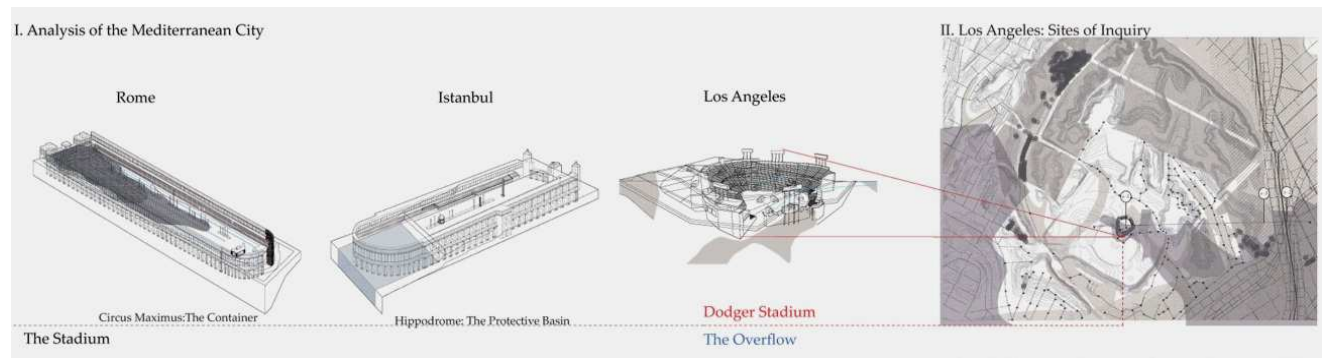

Fig. 8. Imágenes tomadas de la propuesta de concurso Drylands Design Competition, marzo 2012. Fuente: Cesia López.

Los dibujos elaborados por Cesia López en su propuesta para Drylands Design Competition en 2012, establecen una interesante comparación entre diferentes tipos de construidos durante el imperio Romano con sus correlatos actuales. sus dibujos ponen de manifiesto la riqueza que aporta el agua a estos espacios monumentales, y la diferencia con la situación actual, donde a excepción de algunos casos sobre todo ornamentales, circula en su mayoría entubada por un subsuelo invisible, que apenas forma parte de la conciencia colectiva de lo que es la ciudad.

Desde otro punto de vista, la relación con el agua y con las cuencas locales vuelve a poner en contacto agua y espacio público: las zonas inundables próximas a ríos y arroyos eran tradicionalmente ocupadas por programas efímeros, que próximos a las zonas consolidadas, acogían el mercado como centro neurálgico de la vida pública. En esta situación, el agua ocupaba el espacio eventualmente, como resultado de las dinámicas hidrológicas, y compartiéndolo con el intercambio y el contacto social. 
Estas relaciones espaciales entre el agua y el ámbito de lo público, derivadas en parte por su equivalencia geométrica dan pie a identificar dos ideas importantes para la construcción de espacios actuales: la integración de los procesos físicos y los sistemas vivos en el espacio urbano y la propuesta de otra monumentalidad donde lo público se apoya en lo paisajístico.

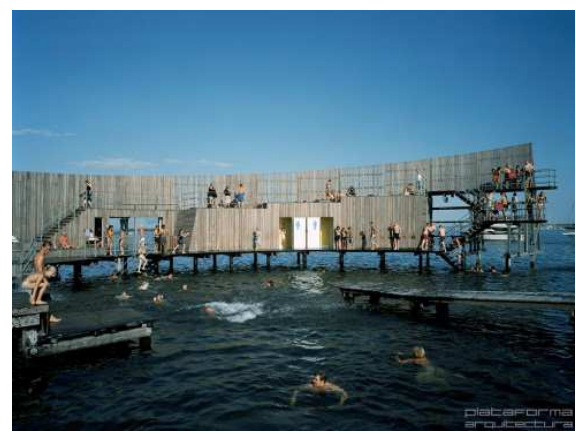

Fig. 9. Spiraling Wood Sea Bath - Denmark, arquitecto Fredrik Pettersson. Fuente: White Architects.

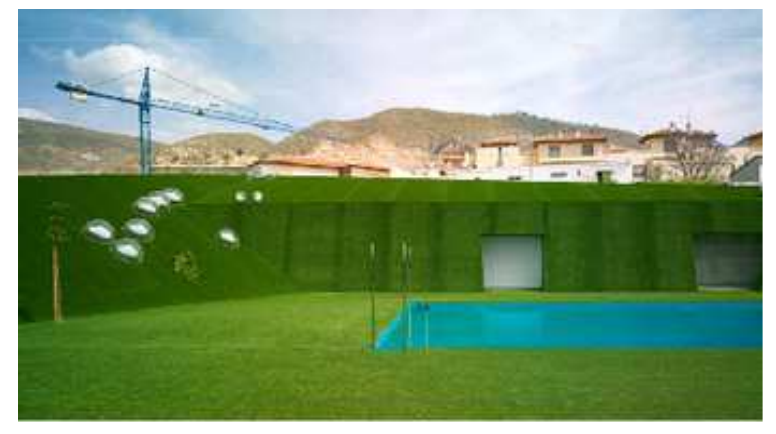

Fig. 10. Piscina municipal en un valle artificial en Lobres, Granada. Fuente: DJ arquitectura.

\section{Construcción de lugares y experiencia somática.}

La arquitectura ha tratado en general de construir entornos estables, frente a las dinámicas del paisaje. Los esfuerzos para detener la erosión y otros procesos de cambio que el agua introduce a su paso han sido enormes. En la construcción del espacio urbano, acciones de explanación, dragado, impermeabilización $\mathrm{y}$, canalización han tratado de borrar los rasgos físicos, topográficos e hidrológicos, que suponían presencias molestas como charcos, barro, humedades, etc. Sin embargo, desde la incorporación de la ecología a las herramientas del urbanismo y el entendimiento de la ciudad como un ecosistema, iniciada en los años 60 con el trabajo de Ian McHarg cambia la aproximación. Lejos de anular la presencia de los procesos físicos trata de integrarlos, lo que supone soluciones diferentes que buscan beneficios ambientales y una cierta desmineralización del entorno urbano. Desde los estudios de paisajismo, durante las últimas décadas se han propuesto numerosas soluciones que incluyen las condiciones hidrológicas de un paisaje como punto de partida, considerando que los fenómenos relacionados con el agua enriquecen la experiencia del espacio, le otorgan variabilidad y lo integran con su contexto regional. 
La lluvia y la nieve, los charcos, los movimientos del agua en forma de mareas o crecidas estacionales, o la integración de las infraestructuras de captación y depuración, requiere de un proyecto caracterizado por la adaptabilidad a lo variable. Estos fenómenos aportan una riqueza sensorial y plástica al espacio que trasciende los beneficios ambientales y transforma la experiencia que tenemos del espacio. Al mismo tiempo otorga una identidad específica a la construcción de ciudad. Frente a la urbanalización (Muñoz, 2008) de los tejidos indiferenciados que constituyen la periferia generalizada de las ciudades a nivel global, la hidrología es específica. Nos acerca a la construcción de lugares en el sentido antropológico, como los definía Marc Augé, donde es el propio espacio el que aporta la identidad al grupo.

\section{Ambientalismo monumental.}

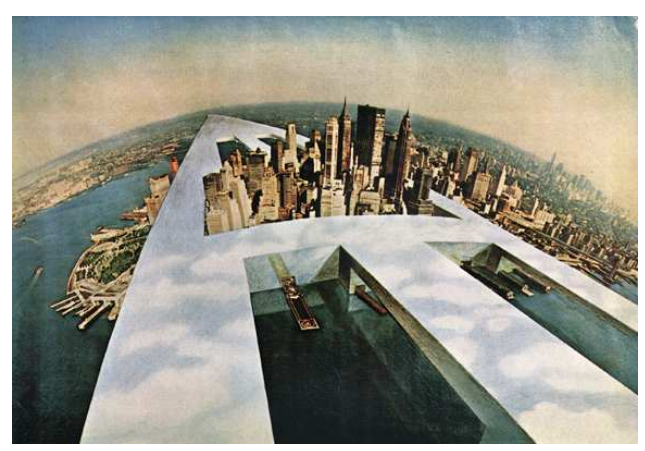

Fig. 11. Superstudio, Monumento continuo, 1969. http://unit607.com/Superstudio

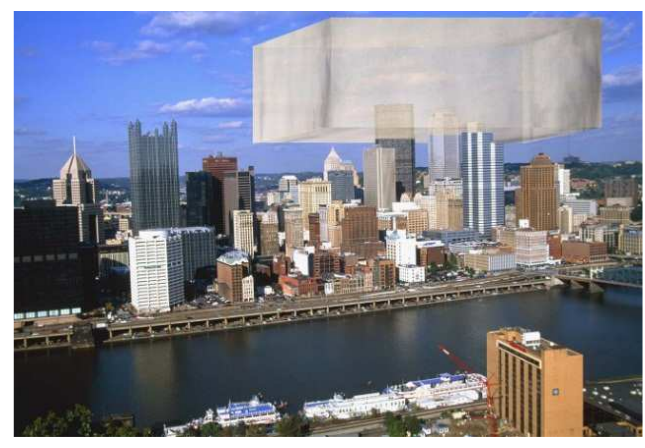

Fig. 12. David Gissen. Reconstruction: Smoke (2006-2010). Recreación del aire histórico de la época industrial en Pittsburgh. http://places.designobserver.com/feature/dangers-inthe-air-aerosol-architecture-and-invisiblelandscapes/18918/

En su artículo Monumental environments, David Gissen (2012) propone:

visualizar una concepción del ambiente desde la arquitectura que es más histórico que estadístico, más representacional que emocional, mas cosa que flujo, y absolutamente mas monumental que envolvente... pensar más allá que el ambiente vectorizado en arquitectura, es pensar más allá de la sublimación científica, tecnológica y naturalista que domina nuestro entendimiento y experiencia del ambiente. De esta forma se propone lo estético como un tipo de entendimiento expe- 
rimental de carácter a-científico que puede otorgar al ambiente un carácter monumental, potencialmente objetual (traducción C. González Vives).

Para transformar algo omnipresente como el medio en algo objetual, se requiere una operación que le otorgue visibilidad, forma y separación.

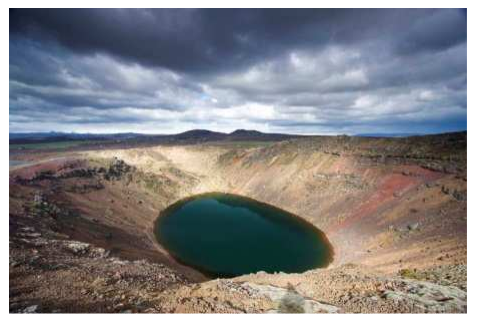

Fig. 13. Cráter volcánico con agua, Islandia.

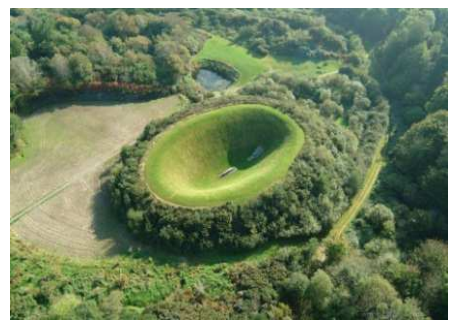

Fig. 14. Irish sky garden crater. Fuente: James Turrel.

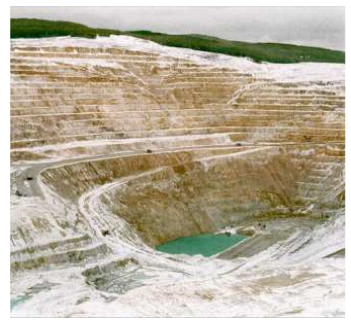

Fig. 15. Mina $\mathrm{n}^{\mathrm{o}} 17$.

Fuente: Edward Burtynsk

Estas imágenes donde el agua es un centro absoluto de un espacio introvertido, aislado del exterior, contienen en su forma la idea de objetualizar el agua, que pasa de envolvernos como vapor y como líquido, entrelazada con el aire que respiramos, o el suelo que pisamos. Esta disposición, esta coincidencia de formas y programas es una posibilidad de recuperación para el agua de un carácter simbólico y monumental que ha sido relegado por sus cualidades utilitarias, sublimadas por la generalización de las infraestructuras de suministro y saneamiento.

Lo monumental referido al medio creo que supone una transformación notable de la idea que introdujo el paisajismo en Estados Unidos con los parques naturales y los grandes parques urbanos como espacios públicos y monumentales de la joven sociedad americana (Ábalos, 2007), basada en el entendimiento de naturaleza y paisaje como patrimonio común e identitario, impregnada de un carácter más épico y de una ilusión de dominación/preservación. en el caso del agua, esa monumentalidad iba asociada a la racionalización de los recursos hídricos, materializada en las grandes presas que simbolizan un nuevo paisaje público como nuevas "pirámides democráticas" (Mumford, 1941). Este cambio de paradigma, hacia una nueva visión integradora, toma como referente el parlamento de las cosas (Latour, 1991), en el que lo político se extiende a los procesos naturales, los acomoda y los respeta, estableciendo acuerdos entre ecología y sociedad. 
Con la imaginación de una ciudad esponjosa y filtrante, con una multiplicidad de grandes concavidades que se abren hueco en la densidad construida, se trata de señalar en el agua urbana, el agua de la lluvia, de los charcos, de la condensación y de las inundaciones, que siempre ha tenido connotaciones negativas en la historia de la arquitectura y del urbanismo, la capacidad simbólica y estética que ha identificado agua como origen de vida, como purificación y limpieza, como frescor. Para cambiar la mirada sobre presencias que han sido incómodas, o incontrolables, se requiere el proyecto de un espacio urbano capaz de integrarlas y hacerlas entrar en resonancia, estableciendo un vínculo con la larga tradición histórica de valoración del agua como bien primordial en un paisaje árido y semiárido caracterizado siempre por la escasez.

\section{Bibliografía.}

ABALOS, I. (2005): Atlas pintoresco. Vol. 1: el observatorio, Gustavo Gili, Barcelona.

ALLEN, S. (1999): The thick 2D, Routledge, London.

Auge, M. (1993): Los no-lugares: espacios del anonimato. Una antropología de la sobremodernidad, Gedisa, Barcelona.

BANHAM, R. (1978): Megastructure: Urban Futures of the Recent Past, Thames and Hudson, London.

FRAMPTON, K. (1994): Toward an urban landscape, Columbia Documents $\mathrm{n}^{\mathrm{o}} 4$, Nueva York.

LATOUR, B. (2007): Nunca fuimos modernos: Ensayo de antropología simétrica, Siglo XXI de España Editores, S.A., Madrid.

MCHARG, I. (1969): Design with Nature, Natural History Press, Nueva York.

MUMFORD, L. (1941): The sky line: architecture of power, New York.

MuÑOZ, F. (2008): Urbanalización. Paisajes comunes, lugares globales, Gustavo Gili, Barcelona.

WALDHEIM, C. (ed.). (2006): The Landscape Urbanism Reader, Princeton Architectural Press, Nueva York. 